\title{
EDUCATION IN ZIMBABWE: AN INTERVIEW WITH CATHRINE KAZUNGA
}

\author{
Vincentas Lamanauskas \\ Šiauliai University, Lithuania
}

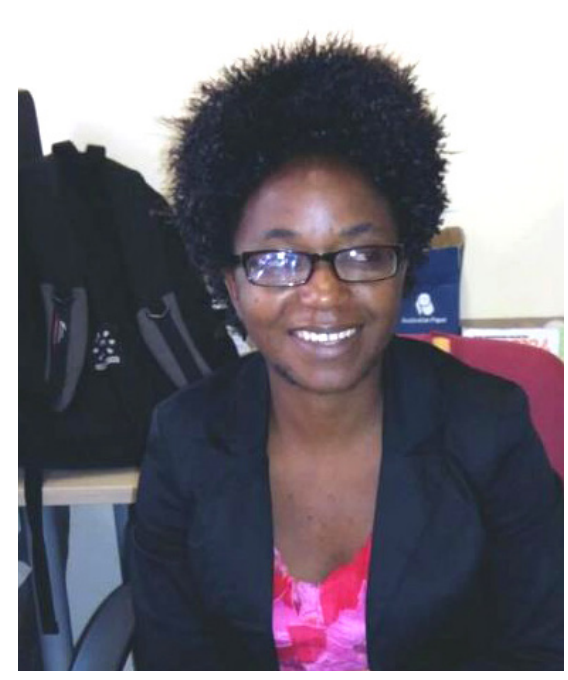

Cathrine Kazunga is a full time student studying $\mathrm{PhD}$ in Mathematics Education with University of KwaZulu - Natal. University of KwaZulu-Natal is one of the most reputable institutions in South Africa, among the institutions with mathematics education as their main topics of research activity. She has twelve years of teaching experience in rural and urban secondary schools and ten years tertiary education of learning and teaching experience in Zimbabwe. She is an emerging researcher who has so many peer reviewed publication of three journal publications and four conference proceedings. It is possible to contact her via e-mail: kathytembo@gmail.com

Introduce yourself briefly to the journal readers

I am a PhD student in South Africa. My research area is Linear Algebra; I am looking at the Action-Process-Object-Schma theory analysis in conceptual understanding of matrix algebra by undergraduate mathematics students. I am an awardee of Organisation for Women in Science for the Developing World fellowship. This fellowship gave me the opportunity to attend and present research work to some of the mathematics education conferences such as 24th Annual Conference of Southern African Association for Research in Mathematics, Science and Technology Education and The Tenth Southern Hemisphere Conference on the Teaching and Learning of Undergraduate Mathematics and Statistics - Elephant Delta Conference which was held in Port Elizabeth and I even participated under technology in Southern African Association for Research in Mathematics, Science and Technology Education research school.

It would be interesting to get a bird's-eye-view of the education system in your country in general, that is from primary to tertiary level. Can you describe the education system in your home country?

Education system in Zimbabwe is divided into two ministries, that is primary and secondary education are under the Ministry of Primary and Secondary Education and 
tertiary education is under the Ministry of Higher Tertiary and Technology Education. The ministries are regulated by Acts of Parliament. The education system in Zimbabwe entails 13 years of primary and secondary school education. The primary and secondary education runs throughout the year with three terms and each term runs for three months. The school year has a total of 40 weeks with three terms and a month break in-between each term. The pupils take their national examinations during the third term in November and June examinations at ' $\mathrm{O}$ ' level and ' $\mathrm{A}$ ' level.

\section{Defining Primary School Education}

Primary school education is when pupils receive basic education. It is emphasized from zero years to twelve years or thirteen years. The primary education is divided into three categories that is Early Childhood Development Education for pupils from zero years to five years, infant education for grades 1 to three and the junior level that is grade four to seven. There is a difference in conditions first between rural and urban environments in terms of medium of instructions for primary school pupils. In rural areas teachers use vernacular languages as medium of instructions, whereas in urban areas English is the medium of instructions most of the times. During the seventh year students take national examinations in: "Mathematics, English, Shona or Ndebele and General Paper.

\section{Early Childhood Development level}

It is a level for primary education children between the ages of zero years to five years. They are taught basic education, motor skills and manipulative skills as well as basic concrete mathematical concepts. The transition from Early Childhood Development Education to grade one is marked by a graduation ceremony. Early Childhood Development Education is compulsory education at primary schools and mandatory for the child to proceed to the next level. Sometimes this level in Zimbabwe is coded as zero grade.

\section{Grade ECD -7}

Primary education level is subdivided into two categories: infant level (ECD-Grade 3) being led by a teacher- in- charge and junior level (4-7) being headed by teacher-in -charge junior. The teachers -in -charge supervise and monitor the learning taking place at their levels and report direct to headmaster and deputy headmaster/mistress. Most Zimbabwean children begin grade 1 in their sixth year of age with an insignificant number beginning at the seventh year. The most recommended age is seven years. For primary schools in urban areas the medium of instruction is English with some code switching for learners understanding, with Shona and Ndebele taught as a subject, for rural schools mother tongue is the medium of instructions, but for the transition Grade 3 English is recommended. Curriculum is nationalised with prescribed textbooks all in English. The primary curriculum consists of the following subjects: English, Mathematics, Shona or Ndebele or Shangaan or Nambya or Ndau or Venda, Music education, Art Education, Religious and Moral Education, Agriculture, Environmental Science, Social Studies, Computer Science, Physical 
Education, HIV and AIDS Education. The seven years of primary schooling culminate in four nationally-set Grade 7 examinations in English, Mathematics, Ndebele or Shona or Shangaan and General Paper. General Paper is a combination of subjects such as Agriculture, Environmental Sciences, Religious and Moral Education, Home Economics, Social Studies and Music Education. In primary school education one teacher teaches all the subjects, except Computer Science, Home Economics, Music Education and Agriculture. There is no subject specialisation.

\section{Secondary School Education}

Secondary School consists of three levels: ZJC (Zimbabwe Junior Certificate) which includes Forms 1 and 2; "O" level which includes Forms 3 and 4; and "A" level which includes Forms 5 and 6. Students take public national examinations in the final year of Ordinary level and final year of advanced levels. Subjects are taught by subject specialists.

\section{Forms 1-2 (Zimbabwe Junior Certificate)}

Students entering Form I, usually are aged 12-13. There are competitions for places in the private and mission schools. Getting a place at a boarding school is by merit based on Grade 7 examination results and on the interviews and placement tests. Government schools take students by zone and then all the rest of the places to those with the best qualifications from outside their catchment zones. The ZJC Core Curriculum consists of 8 subjects: English, Shona or Ndebele, Mathematics, Science, History, Geography, Religious and Moral Education, Commerce and Practical Subjects (such as Art, Building, Food and Nutrition, Fashion and Fabrics, Woodwork, Agriculture, Metalwork, Technical Drawing, Computer Science so on). Zimbabwe phased out the ZJC examinations in 2001, but has maintained the same curricular framework for general Form 1 and 2 education. Zimbabwe Junior Certificate is no longer having public examinations by the end of two years. The phasing out of Zimbabwe Junior certificate examination was as a result of financial constraints and lack of relevance of the qualifications on the job market. However, Zimbabwe Junior Certificate Examination was a good examination because it was essential to prepare students for ordinary level examinations. Zimbabwe Junior Certificate Examinations promoted concept development especially in Mathematics. In Zimbabwe secondary education curriculum is in progression from form one to form four, then from form four to six and even at tertiary level.

\section{Forms 3-4 (Ordinary Level, O’ Level)}

Based on their Form 1 and 2 reports, students are assigned to courses and tracked classes for their O' level studies for Forms 3 and 4. Students typically write their ' $O$ ' level exams when they are 15-17 years old. In government schools in the high-density urban townships and in the rural areas, students are restricted in their options and usually are only afforded the opportunity to take 8 or 9 subjects. Elite private schools often allow and encourage students to take up to 12 or 13 subjects for "O" level exams. Since 2002 GCE or ' $\mathrm{O}$ ' level examinations were localized and conducted by a local examination board called Zimbabwe Examination Council (ZIMSEC). Marks from the highest to lowest are A, B, C, D, E, U with A, B, and C as passing marks. However, most independent school students 
are writing both local and Cambridge exams. To receive a passing ZIMSEC 'O' level GCE certificate, a student needs to have passed at least five subjects including English language with a grade of " $\mathrm{C}$ " or better. The English and Mathematics ' $\mathrm{O}$ ' level examinations are the core subjects for tertiary education, jobs and travel and three other subjects constitute a full certificate.

Subjects currently on offer for O' level examinations include:

Discipline

Sciences

Liberal Arts

Languages

Practical Subjects

Arts

Commercial Subjects
Subjects

Biology, Chemistry, Physics, Physics with Chemistry, Integrated Science, Mathematics, Additional Mathematics

English Literature, Religious Education, Geography, History

English, Shona, Ndebele, French, German, Venda

Woodwork, Metalwork, Agriculture, Technical Drawing, Fashion and Fabrics, Food and Nutrition, Computer Science, Building

Art, Music

Accounts, Commerce, Economics, Business Studies

Forms 5-6 (Advanced level, A’ level)

Entrance into A' level programs is quite competitive, with the majority of ' $\mathrm{O}$ ' level students either returning to small-scale farming, entering the work force or proceeding to a vocational course, a technical school or a nursing or teaching college. With Zimbabwe's rate of unemployment currently surpassing $60 \%$, many ' $\mathrm{O}$ ' level graduates face bleak employment prospects. Only those with the best scores manage to find a high school place in an Advanced level program. At the Advanced level, students choose among science, commercials and art subjects to study for Forms 5 and 6 . The majority of students take three subjects at A' level, with a few very gifted students at elite schools opting for four subjects. In addition, some A' level students take "English for Communication", which before 2004 was called General Paper, a very challenging exam that assesses both English writing skills and knowledge of current events both nationally and worldwide. English for Communication is marked on a 1-9 scale with 1 as the highest mark and a 1-6 as a pass. Starting June 2002 exams, 'A' levels were localised and run by ZIMSEC. It is common for a capable student to have higher ' $O$ ' level exam marks than her/his ' $A$ ' level exam marks or vice versa. Students are free to write both Cambridge and ZIMSEC 'A' level exams. 
A' level subjects currently offered in Zimbabwe include:

Discipline Subject

Sciences Biology, Chemistry, Physics, Mathematics, Further Mathematics

Commercials Management of Business/Business Studies, Economics, Accounts, Computer Science

Arts $\quad$ English Literature, Geography, Shona/Ndebele Language and Literature, Divinity, History, French, Art, Music

Most of the time science students sit for four or five subjects and pass all very well.

\section{Tertiary Education}

\section{Vocational training colleges}

The Ministry of Higher Education and Technology regulates practical skills training programs at a variety of state and privately owned vocational training centres in the major urban hubs.

\section{Polytechnic Colleges}

Polytechnic training colleges cater for more advanced skills in courses like engineering, information technology, clothing and textiles, computer science, food science, secretarial studies, Wood technology, further teacher education and building.

\section{Teacher training colleges}

Training providers will recruit suitable trainees on a first-come, first-served. The teacher training education is subdivided into two: Primary teacher training education and secondary teacher training education. Teachers`colleges award Diploma in Education.

\section{Primary teachers' colleges}

In primary teacher training they have two types of teachers that is Early Childhood and Development (ECD) teachers who teach ECD A - Grade 3 and general primary teachers teach Grades 1-7.

Primary school teacher training colleges normally require minimum of five ' $\mathrm{O}$ ' level passes including mathematics and English. The shortlisted candidates go for oral selection interviews. The primary teacher trainees are taught 17 subjects. These include subjects taught at a primary school: English, Mathematics, Shona or Ndebele or Shangaan or Nambya or Ndau or Venda, Music education, Art Education, Religious and Moral Education, Agriculture, Environmental Science, Social Studies, Computer Science, Physical Education, HIV and AIDS Education, Theory of Education (Philosophy of education, Psychology of Education, Sociology of Education), Information Technology, Professional Studies, Main 
Study Subjects. Primary teacher training course is a three year course under 2-5-2 rule. That is two terms in the college, five terms in the field practising under mentorship of a qualified teacher and two terms in college finishing the course.

Secondary teachers' college training course

The secondary teacher training course can be divided into two categories that is two year programme and three year programme. Two year programme is for the ' $A$ ' level graduates and three year programme for ' $\mathrm{O}$ ' level graduates. In most times ' $\mathrm{O}$ ' graduates are recruited for practical subjects such as building, Agriculture and Fashion Fabrics. The course is equivalent to a university first year programme.

The largest sector of higher education is teacher education colleges, which are situated mostly in urban centres, much like technical colleges. The teacher education colleges offer specialisation in numerous subjects, such as languages, arts, mathematics, social sciences, sciences, and commercial and other technical fields, theory of education, professional studies, communication skills. While each college has a unique curriculum, there are certain areas where the curriculum is standardized such as science, mathematics, English, Shona/ Ndebele, and professional foundations and theory education. Whereas some colleges train both primary and secondary school teachers, some specialize in training just one level. Because of the special relationship that exists between the University of Zimbabwe and teacher training colleges, the diplomas that are granted are university certificates.

In general, the Ministry of Higher Tertiary Education and Technology administers technical and teacher colleges, with teacher colleges having a somewhat differing status, as the awarding of diploma certificates illustrates. Teacher colleges follow the standard administrative structure of government colleges, but unlike technical colleges, they have an academic board, which is called the Associate College Centre academic board. This board comprises all college principals, representatives from the Ministry of Higher Education's Teacher Education section, and university representatives. The board is charged with the responsibility of monitoring all academic programs in the colleges. Technical college administrative structure comprises three bodies. The first is a college advisory council (CAC), which advises the principal on how to run the institution smoothly. Members are appointed by the Minister of Higher Education to advise the principal and help meet commerce and industry workforce needs. The second board is the college administration (CA), which is the administrative organ of the college; it includes the principal, the bursar, and the vice principal. The final group is The College Board of Studies Committee (CBSC), which is chaired by the college principal and is responsible for monitoring academic programs as well as overall administration. Senior administrators of the college join the principal on the board meetings.

\section{Universities}

There are many universities in Zimbabwe offering diplomas and degrees in various disciplines. These include state and private funded ones, a women's university, and a distance learning Open University. It has ten faculties, and a variety of specialist research centres and institutes. Some universities use schools such as Chinhoyi University of technology, 
and some use both schools and faculties. The faculties are headed by deans, followed by chairpersons, head of department, subject coordinator, then lecturers, however the structure varies from university to university.

The curriculum followed are: Arts, Sciences, commercials, Law, medicine, engineering, education, social sciences, humanities and agriculture. The programmes are either on block release, distance learning, part time and full time. Block release programmes are those programmes whereby a student visits the university for short period. They are taught by lecturers and equipped with notes and modules. Usually block release programmes are ideal for students who are employed.

Distance learning programmes thus where students are receiving learning materials from the lecturers as softcopies and hardcopies. Usually students learn whilst at home.

Part time programmes are those done during the evening. The students are doing the same courses, same assignments and same examinations as conventional students. Full time or conventional programmes thus where students reside at the campus attending their lectures. Graduates from universities acquire different degrees, such as Engineering, that leads to be engineers, Law, they become company secretaries etc.

\section{It is obvious that teaching is a very important profession. Teachers need to be well- educated. How teachers are educated in your country?}

There are several programmes made to educate teachers in Zimbabwe. There is teacher in-service programmes, teacher capacity building programmes, seminars and workshops, distance learning, block release and full time programmes. Teacher -in service programmes thus where a teacher enrols for a qualification above his/her qualification. For example a certified teacher may do in-service course to upgrade his/her qualification. Teacher capacity building programme refers to a programme, where teachers enrol for a programme that addresses critical skill shortage in schools, for example Mathematics teachers. Usually the government of Zimbabwe sponsors it. Seminars and workshops refer to a programme as on the job training. Most of the teachers in Zimbabwe are well trained from a teacher college or a recognised university. Few teachers who hold a teaching degree or diploma without the theory of education are encouraged to go back to the university or teacher college to acquire the pedagogical knowledge. The certificate is coded Post Graduate Diploma in Education (PGDE)

\section{When should children start formal schooling in your country?}

The children start formal schooling after three years, then they proceed from ECD A to ECD B, that is characterized by a mini graduation done at a primary school or at a recognised preschool. 
It is a well-known fact that students' motivation to learn is a key element in education. If children are motivated to learn and if we enable each one to learn effectively, we will have an education system with a great performance level. What about students' motivation to learn in your country?

Both primary and secondary schools hold speech and prize giving days to give prizes to students for outstanding academic performance and behaviour. They also hold parent days were parents come to school to see the work of their child and teachers make recommendations so that the child is motivated to work hard. The teachers are discouraged to make demotivating comments like poor, useless. They are encouraged to write motivational comments like you have the potential to do better and so on. After one perform well at ' $O$ ' level they can be awarded a scholarship to study ' $A$ ' level and their names are displayed in the public media to motivate other students to work hard. The same applies to 'A' level outstanding students. They are awarded a scholarship to study at any university in Zimbabwe and their names are displayed in social media too like newspaper. Students from different schools compete in Olympics, say for mathematics at ' $A$ ' level and the best students get an award.

Students are motivated by interacting with role models who they achieve through education. The career and guidance programmes and open days are eye openers for students to real world. This will motivate them to work hard with an informed stance, getting simple instructions that is suitable for all levels of students, giving instructions that articulate their current predicament.

\section{What are the qualities of a good teacher from your point of view?}

The qualities of a good teacher are the ones of being knowledgeable, punctual to work, role model, smart, caring, respectful, morally upright, fair, God fearing, hardworking, patient, giving encouraging comments, supportive, cheerful.

A good teacher has good content knowledge, subject specific knowledge, technological knowledge and pedagogical content knowledge. A good teacher knows the content of the subject(s) which s/he will be teaching, all the concepts to be covered, the teacher knows how the concepts, images are being formed. The teacher is willing to learn new technical skills and teaching methods to improve the learner's understanding.

\section{It is clear that each country's education system has both advantages and disadvantages. Could you briefly describe your country's basic education system challenges?}

In Zimbabwe there are a plethora of challenges bedevilling the education system, these are students taught by semi-skilled teachers without pedagogical knowledge and content, for example, university graduates without education. The technological challenges, that is, there is a lack of proper gadgets such as computers, projectors, lack of knowledge of how to use technology. Teachers are trained theoretically without proper hands on, for example, information technology. Some teachers came from universities with good passes in information technology but without proper practices. Science subject schools do not have proper laboratories. So, students end up theorizing and pass the examinations 
without practical knowledge. The other challenge is the examination leakage, for example, Mathematics. There are challenges of funding school programmes and another absenteeism of teachers, especially in rural schools, poor accommodation for teachers, and poor infrastructure, especially in satellite schools established in the turn of the $21^{\text {st }}$ century.

I do hope that our readers will be very enthusiastic about the possibility to understand some features of the educational system in your country. It was really an exciting opportunity to communicate with you. I also think that all the mentioned education challenges will be successfully resolved. Thanks again, and I hope to hear from you in the near future. Good luck

Note: This interview was performed 15 January 2016, in Pretoria, South Africa. 